\title{
Complexity and Uncertainty regarding Superannuation Do Not Explain Key Decisions Taken by Members
}

\author{
Necmi K. Avkiran, Elizabeth Zhu \\ School of Business, The University of Queensland, St Lucia Campus, Brisbane, Australia \\ Email: n.avkiran@business.uq.edu.au
}

How to cite this paper: Avkiran, N.K. and Zhu, E. (2018) Complexity and Uncertainty regarding Superannuation Do Not Explain Key Decisions Taken by Members. Theoretical Economics Letters, 8, 2063-2081. https://doi.org/10.4236/tel.2018.811135

Received: June 4, 2018

Accepted: July 29, 2018

Published: August 2, 2018

Copyright (c) 2018 by authors and Scientific Research Publishing Inc. This work is licensed under the Creative Commons Attribution International License (CC BY 4.0).

http://creativecommons.org/licenses/by/4.0/

\begin{abstract}
Superannuation in Australia represents the largest investment in the country in the managed funds industry. Yet, people without appropriate qualifications are required to make financial decisions for their future under government legislation. We capture complexity and uncertainty as a way of explaining key decisions, using partial least squares structural equation modelling (PLS-SEM). Complexity explains key decisions more than uncertainty. Based on the answers given to open-ended questions, members are at a loss to make key decisions for their future, partly due to the non-transparency of superannuation and changing government rules.
\end{abstract}

\section{Keywords}

Superannuation, Key Decisions, Complexity, Uncertainty, Members

\section{Introduction}

Superannuation funds in Australia represent the largest investment in the country within the managed funds industry. The Australian Prudential Regulation Authority (APRA) reports assets under management of $\$ 2.1$ trillion as at 30 June 2016 [1]. Furthermore, superannuation funds represent one of the largest investment areas in the Australian economy [2]. According to the OECD, in 2014 Australian assets under management regarding superannuation funds represented $110 \%$ of the GDP; the contribution by employees (includes voluntary contributions), employers and the government was $7.5 \%$ of the GDP [3]. Yet, people without appropriate qualifications are required to make financial decisions for their future under government legislation. That is, the Australian population is expected to select types of asset allocations, or select pre-mixed options where 
asset allocations are determined by trustees [4]. Various studies have reported complexity and/or uncertainty in relation to Australian superannuation funds [5]-[12]. In this article, we are the first to capture complexity and uncertainty (latent constructs) as a way of explaining the key decisions made by members using partial least squares structural equation modelling (PLS-SEM).

The Australian federal government recently promised to encourage innovative retirement products designed to minimise market risk, inflation risk and longevity risk (see the Financial System Inquiry by [13]). Superannuation funds therefore have a greater incentive to create products that are more complex ${ }^{1}$. On the other hand, the latest survey results of financial literacy ${ }^{2}$ in Australia show that adult understanding of superannuation declines as members' age rise, suggesting that an increasing number of members lack the financial knowledge and its application to selected superannuation investments. The complexity of superannuation products and uncertainties relating to members can further hinder the engagement of fund members.

The ability to understand superannuation products and make investment decisions has a direct impact on members' future personal welfare. Earlier studies find that Australian investors are unable to distinguish high-performing superannuation funds [14]. More recently, [15] report a significant heterogeneity in the appropriateness of superannuation savings in Australia, and conclude that a one-size-fits-all approach will not work. Using survey data on a sample of members of UniSuper-one of the largest superannuation funds in Australia-we provide new evidence on the impact of complexity and uncertainty in explaining key decisions made by fund members.

Superannuation funds will continue to rise, with the current legislated employer contribution set to increase from $9.5 \%$ to $12 \%$ of income by July 2025 [16]. The Australian federal government's recommendation is that investors consolidate their retirement savings into a single fund [17]. Reference [18] finds that, during the global financial crisis of 2007-2009 the majority of fund members did not change their investment strategies; furthermore, those who did change their investment strategies reduced their exposure to equity when the market was at its lowest, thus locking in losses. In addition, some research also finds that individuals who are the most active in investing in discretionary Australian superannuation products perform worse than their peers [7]. It is, therefore, important to further explore whether complexity and uncertainty drive key decisions by members.

Section 2 further develops the conceptual model; Section 3 discusses the method and data; Section 4 reports the PLS-SEM analyses and robustness tests; and, Section 5 summarises and discusses the key findings, including some of the ${ }^{1}$ See, for example,

https://www.unisuper.com.au/about-us/news/2015/12/10/unisuper-unveils-innovative-cipr (date accessed 20 April 2017).

${ }^{2}$ See the most recent ANZ survey of adult financial literacy in Australia. Source: https://www.anz.com/resources/5/4/54720a2d-a540-49f0-b0a7-62f1ffb922e6/adult-financial-literacysurvey-summary.pdf?MOD=AJPERES 
comments to open-ended questions.

\section{Core Conceptual Framework}

We further develop the survey instrument in this section (see Appendix). Reference [19] highlight the problems with an ageing population in terms of cognitive decline, and thus, falling financial literacy. Reference [20] report that, as cognitive function declines investments decline and reduced participation in financial markets follows. A focus group study by [6] reports that people of all ages understand the significance of superannuation but consider complexity and uncertainty (behavioural drivers) as challenges. The authors report complexity as proliferation of planning tools, investment choices (Q2), insurance products (Q1), difficulty of navigating superannuation funds (Q4), various investment strategies (Q3), and fees and charges (Q5). They discuss uncertainty in the context of marital status $(\mathrm{Q} 1)$, relocation, raising children $(\mathrm{Q} 2)$, health $(\mathrm{Q} 4)$, and employment opportunities (Q3) (see the Appendix). Reference [6] also relate lack of confidence to complexity and uncertainty.

We now turn to other literature that further supports the survey items selected. Reference [21] indicate that, in order to reduce complexity, individuals use shortcuts for processing large quantities of information, but this approach can result in incomplete analysis and errors. Reference [11] report that more complex pension plans significantly raise costs and reduce savings; we include fees and charges in the survey for complexity. Reference [10] state that Australian superannuation savings are facing high regulatory complexity.

Reference [8] raises the issue of uncertainty in relation to financial market outcomes on investments; this is the reason we question the members about their confidence under uncertainty (Q5). Similarly, reference [9] raises the issue of investment risk, but also focuses on political risk (members earning less due to changes in regulation) and longevity risk (members outliving savings); health is included under the questions on uncertainty to address longevity risk. Reference [12] further states that because of the reliance on investment gains and risks such as longevity, Australian superannuation funds need protection from the consequences of the globalised financial system. The problem of low financial literacy is more relevant in lower income individuals who consistently underperform on financial literacy assessments [22].

\section{Method and Data}

\subsection{Method: Partial Least Squares Structural Equation Modelling (PLS-SEM)}

For the first time in this field, we apply PLS-SEM to evaluate how the two exogenous constructs explain the endogenous construct, i.e. complexity and uncertainty explain key decisions made by members (see Figure 1). PLS-SEM is a non-parametric, multivariate approach based on iterative OLS regression designed to maximise explained variance in latent constructs [23] [24]. Latent 


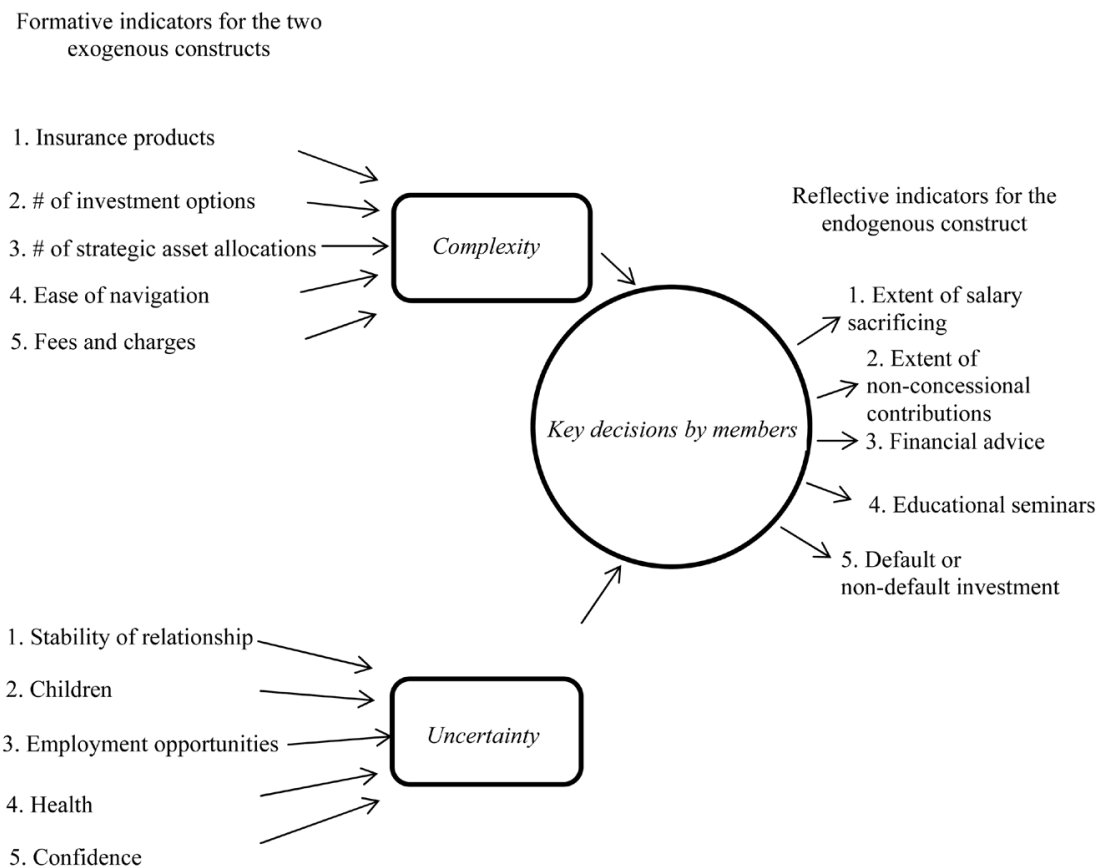

Figure 1. The theoretical model of PLS-SEM.

constructs (i.e. complexity, uncertainty and key decisions) are indirectly observed through a number of indicators, i.e. the survey items in this study. PLS-SEM is known to be an appropriate method when working with composite models of prediction in exploratory research; it is also robust with skewed data [25] [26].

It is particularly relevant with data found in business databases where distributional constraints are not likely to be met. The three main reasons for selecting the PLS-SEM approach are small sample size, presence of formative indicators, and non-normal data (see Table 1 in [27]). The reader is referred to [28] for a detailed exposition of PLS-SEM.

PLS-SEM has been used in various disciplines such as accounting [29], health care [30], management information systems [31], marketing and strategic management [32], operations management [33], supply chain management [34], and tourism [35]. As a predictive method, PLS-SEM has a wide spectrum of practical applications to managerial challenges. PLS-SEM does allow for critical exploratory research to be undertaken without assuming, say, multivariate normality or large sample sizes that may not be feasible. As such, PLS-SEM can be used to lay the foundation for further studies using methods that make stricter assumptions about the underlying data and sample size.

PLS-SEM models consist of three main components, namely, the structural or inner model (i.e. three constructs in Figure 1), the measurement or outer models (i.e. the formative and reflective indicators), and the weighting scheme. A group of indicators (manifest variables) associated with a latent construct is referred to as a block, and an indicator can only be associated with one construct. 
Table 1. Descriptive statistics on the survey data (full sample).

\begin{tabular}{cccccccc}
\hline & Mean & Median & Min & Max & $\begin{array}{c}\text { Standard } \\
\text { Deviation }\end{array}$ & $\begin{array}{c}\text { Excess } \\
\text { Kurtosis }\end{array}$ & Skewness \\
\hline Salary sacrifice & 1.302 & 0.000 & 0.000 & 19.000 & 2.010 & 12.634 & 2.668 \\
Non-concessional & 0.417 & 0.000 & 0.000 & 5.000 & 0.980 & 3.229 & 2.195 \\
Financial advice & 1.083 & 1.000 & 0.000 & 5.000 & 1.345 & 1.412 & 1.405 \\
Seminars & 1.073 & 0.000 & 0.000 & 5.000 & 1.535 & 0.876 & 1.411 \\
Default vs non-default & 2.711 & 3.000 & 0.000 & 7.000 & 2.166 & -1.240 & 0.057 \\
investment & 3.115 & 3.000 & 1.000 & 5.000 & 1.247 & -0.908 & -0.172 \\
Insurance & 6.862 & 6.000 & 2.000 & 10.000 & 2.622 & -1.137 & -0.241 \\
No of investment & 1.447 & 0.000 & 0.000 & 8.000 & 2.308 & 0.873 & 1.449 \\
Asset allocations & 2.559 & 3.000 & 1.000 & 5.000 & 1.123 & -0.363 & 0.387 \\
Navigation & 2.937 & 3.000 & 1.000 & 5.000 & 1.316 & -1.053 & 0.126 \\
Fees & 1.806 & 1.000 & 1.000 & 5.000 & 1.267 & 0.615 & 1.387 \\
StabilityRelationship & 1.981 & 1.000 & 1.000 & 5.000 & 1.328 & -0.209 & 1.064 \\
Children & 3.083 & 3.000 & 1.000 & 5.000 & 1.518 & -1.417 & -0.117 \\
Employment opportunity & & & & & & & \\
Health & 2.238 & 2.000 & 1.000 & 5.000 & 1.345 & -0.800 & 0.691 \\
Confidence & 2.937 & 3.000 & 1.000 & 5.000 & 1.490 & -1.407 & 0.030 \\
\hline
\end{tabular}

PLS-SEM requires recursive models, i.e. there are no circular relationships or loops and the model is a predictive chain [28] [36]. For the current study, Figure 1 shows the PLS-SEM theoretical model with formative indicators (sources of complexity and uncertainty) and reflective indicators (consequences of key decisions by members). Path coefficients and their significance will determine how much the key decisions by members are explained by the two exogenous constructs, namely, complexity and uncertainty.

Reference [37] discuss the differences between PLS-SEM and covariance based SEM (CB-SEM). CB-SEM can be used to investigate relationships among latent constructs indicated by multiple variables and expects multivariate normal distribution and large samples compared to the population. CB-SEM follows a confirmatory approach to multivariate analysis where the researcher theorises about causal relations among the variables of interest, i.e. this is not exploratory research. Measurement error structures can be modelled via a factor analytic approach in CB-SEM, but it comes at the cost of covariances among the observed variables conforming to overlapping proportionality constraints, i.e. measurement errors are assumed to be uncorrelated [38]. CB-SEM assumes homogeneity in the observed population [39]. Such constraints are unlikely to hold unless latent constructs are based on a highly developed theory and the measurement instrument is refined through multiple stages.

Two of the advantages of PLS-SEM over CB-SEM are (a) a focus on predicting dependent latent variables [40] [41], often a key objective in empirical studies, 
and (b) the ability to accommodate indicators with different scales. In addition to being robust with skewed data because PLS-SEM transforms non-normal data according to the central limit theorem, it is also considered an appropriate technique when working with small samples [28] [42]. To summarise, PLS-SEM is appropriate in exploratory research when using non-normal data with a small sample size (compared to the population) and in the presence of formative indicators.

\subsection{Data}

Australian superannuation funds are divided into three main types (a) not-for-profit (regulated by APRA), (b) retail (regulated by APRA), and (c) self-managed funds (one to four members as trustees, regulated by the Australian Taxation Office). Retail funds offer their members a range of choices and members are advised by brokers and/or financial planners. In this study, we focus on UniSuper (https://www.unisuper.com.au)-a not-for-profit fund. Notfor-profit funds offer a limited number of investment choices compared to other categories, and if a member selects a pre-mixed option, fund trustees determine asset allocations. Data are collected using an online survey instrument (see the Appendix).

The Appendix displays the survey instrument in full. Each construct is surveyed using five questions, followed by an open-ended question. We are interested in capturing the perceptions of superannuation fund members, particularly under the categories of complexity and uncertainty. The first part of the survey asks the members about their key decisions regarding managing superannuation funds (this is based on the current structure of UniSuper regarding defined contributions). We ask about the extent of salary sacrificing and non-concessional contributions; we also ask about the use of financial advice and educational seminars, and ask members to identify their chosen default (pre-mixed) versus non-default (sector) investment options.

In terms of complexity, we focus on the number of insurance products, investment options and strategic asset allocations. We then ask a further two questions relating to the ease of navigating the UniSuper website and the complexity of fees and charges. In terms of capturing uncertainty, we ask the members about their marital status, raising children, employment opportunities, health, and confidence. In terms of scales, both complexity and uncertainty rise to the right. Before finalising the online survey, we fully tested it at the The University of Queensland and received ample feedback.

Starting from the maximum number of indicators in this study pointing at a construct (i.e., five indicators, see Figure 1), the minimum sample size required emerges as 169 assuming a statistical power of $80 \%$, significance level of $1 \%$ and a minimum $R^{2}$ of $10 \%$ (refer to Exhibit 1.7 in [28], p.26); if $R^{2}$ is 50\%, the minimum sample size becomes 26 . Initially we wrote to UniSuper for promotion of the survey; negotiations were inconclusive. We then wrote to the directors of 
human resources of the following universities in every state in Australia requesting bulk emails be sent promoting the online survey: the University of Queensland (accepted, 12,095 UniSuper members), Queensland University of Technology (accepted, 100 UniSuper members), La Trobe University (accepted, 7919 UniSuper members), Deakin University (no response), University of Adelaide (no response), Flinders University (no response), University of New South Wales (no response), University of Sydney (inconclusive negotiations), University of Western Australia (declined), University of Tasmania (declined), Australian National University (no response), and University of Canberra (no response). Out of a potential population of 20,114, 1268 responses were collected, giving rise to a response rate of $6.3 \%$.

Table 1 shows the descriptive statistics for the data collected through the survey. Regarding demographics, we collect information on gender, marital status, number of dependents, age, education, employment, income, and years with UniSuper. The responses show that female respondents account for $60.33 \%$ of the sample, while the proportion of males is $39.67 \%$. Over $50 \%$ of our respondents are married, $23 \%$ are single, and $24 \%$ are in the status of de facto, and $3 \%$ other. We set eight age groups from the youngest of " $18-25$ " to the eldest group of " 56 or older"; interestingly, the eldest age group accounts for $25 \%$ of the sample, the highest proportion among all the age groups, followed by the age groups of “51 - 55” (16\%), “36 - 40” (13\%), “31 - 35” (12\%), “41 - 45” (11\%), “46 - 50” (11\%), and " $26-30$ " (8\%). The youngest group (18 - 25) only stands for $4 \%$, the lowest proportion among the eight groups.

The majority $(84 \%)$ of our sample respondents hold a bachelor degree or above; specifically, $32 \%$ hold a $\mathrm{PhD}, 31 \%$ hold a bachelor degree, and $21 \%$ hold a Masters degree. About three-quarters of our respondents work full-time; the remainder is part-time (13\%) and sessional staff (11\%). The income bracket of our respondents ranges from " 0 - $\$ 10,000$ " (1\%) to "above $\$ 160,000$ " (8\%), with a sample median of “ $\$ 80,001-\$ 100,000$ ”. As to the number of dependents, over half of the sample respondents have no dependent children; about $37 \%$ of the respondents have one or two children; only $7 \%$ have three or more children. Notably, some respondents provided an open answer to this question, saying that even though they do not have dependent children at present, they plan to provide financial support to their grown-up children as needed, for example when their children purchase their first homes. Finally, most of our sample respondents have been with UniSuper for at least three years (91\%) and 59\% of respondents been with UniSuper for at least 10 years.

\section{PLS-SEM Analyses and Robustness Tests}

In this section, we explain the variation in key decisions based on complexity and uncertainty through PLS-SEM, and run robustness testing. We begin by outlining the important statistical criteria for the reflective measurement model (i.e. key decisions), and then we move to interpreting the formative model (i.e. 
complexity and uncertainty) and the structural model (also known as the inner model with three latent constructs). We use the software Smart PLS 3 [43].

\subsection{Reflective Measurement Model}

1) Internal consistency: According to references [32] and [27], composite reliability is a better measure of internal consistency because it avoids underestimation with Cronbach's alpha; it also allows for differences in indicator reliabilities expected by PLS-SEM. A composite reliability of 0.6 is acceptable in exploratory research [32] but values above 0.95 indicate redundancy [28]. Composite reliability is relevant for the reflective measurement model. In the original analysis with 15 indicators, composite reliability is 0.648 .

2) Indicator reliability: Outer loadings greater than 0.7 are desirable [44]. The square of this standardised outer loading is communality, that is, the variation in the indicator explained by the endogenous construct; 1 minus communality reveals the measurement error variance. Reference [32] mention that outer loadings as low as 0.4 are acceptable in exploratory research; if less than 0.4, the reflective indicator can be deleted. Figure 2 shows that the outer loading for non-concessional contributions is significantly less than 0.4 (i.e. 0.303) and should be considered for removal.

3) Convergent validity: Preferred average variance extracted (AVE) is greater than 0.5 ; this ratio implies that more than $50 \%$ of the variance of the reflective indicators has been explained by the latent variable. AVE is interpreted in the context of the reflective measurement model. When examining reflective indicator loadings, it is desirable to see higher loadings in a narrow range, i.e. convergent validity [45]. AVE is 0.293 (low) and the reflective indicator loadings are in the range of $0.303-0.837$ before deletions.

4) Discriminant validity: The Fornell-Larcker criterion states that the square root of AVE must be larger than the correlation of the reflective construct with

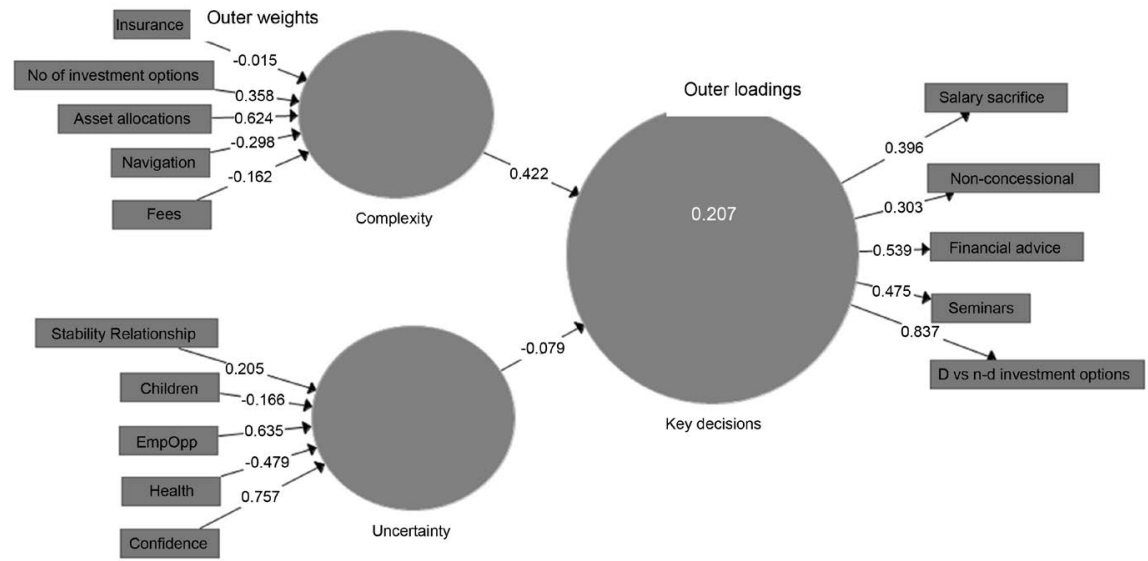

Figure 2. Original PLS-SEM analysis. (The items in each construct are listed in the order of the online survey in the Appendix; "D vs n-d investment options" refers to default versus non-default investment options). 
all other constructs [28]; this criterion is not applicable to formative measurement models and single-item constructs. The square root of AVE is 0.541 and is greater than the construct correlations.

\subsection{Formative Measurement Model}

1) Convergent validity: Higher path coefficients linking the exogenous and endogenous constructs are an indication of convergent validity, implying adequate coverage by the formative indicators [45]. A substantial coefficient of determination is also a good indication of convergent validity. Path coefficients are shown in Figure 2 and the coefficient of determination is 0.207.

2) Collinearity among indicators: Standard errors and thus variances are inflated when collinearity is present. A variance inflation factor (VIF) is computed for each of the explanatory variables in OLS regression. The VIF must be less than 5 [44], i.e. VIF represents the factor by which variance is inflated. Statistically, VIF is the reciprocal of tolerance, where the latter is defined as the variance of a formative indicator not explained by others in the same block. A VIF of 1 means there is no correlation among the predictor variable examined and the rest of the predictors, and therefore, the variance is not inflated. The researcher should consider removing indicators, or combine the collinear indicators into a new composite indicator if the VIF is higher than 5 . The inner VIF is 1.126 , and the outer VIF values are in the range of $1.043-1.670$ indicating that multicollinearity is not an issue in our study.

3) Significance and relevance of outer weights: "Weight" is an indicator's relative contribution; "loading" is an indicator's absolute contribution. To assess significance, one can start bootstrapping with 5000 sub-samples (the recommended minimum by [44]) in order to check whether outer weights are significantly different from zero. Indicators with significant outer weights are kept; otherwise, an indicator can still be kept if its outer loading, that is, its absolute contribution is greater than 0.5. Insignificant formative indicators based on $p$-values (i.e. higher than 5\%) with outer loadings less than 0.5 can be removed from the model for being irrelevant. The indicators of children and health (uncertainty construct) and insurance (complexity construct) are indicated for deletion.

\subsection{Structural Model}

If the reflective and formative measurement models are not reliable, we become less confident in the structural model. An analysis of the structural model is an attempt to find evidence supporting the theoretical model, i.e. the theorised relationships between exogenous constructs (i.e. complexity and uncertainty) and the endogenous construct (i.e. key decisions).

1) Predictive accuracy, coefficient of determination $\left(R^{2}\right)$ : This statistic indicates the extent to which the exogenous constructs are explaining the endogenous construct. According to reference [28] and [44], an $R^{2}$ of 0.25 is weak, 
0.50 is moderate and 0.75 is substantial. Unless the adjusted $R^{2}$ is used (for a formal definition, see [28], p.199), this coefficient can be upward-biased in complex models where more paths are pointing towards the endogenous construct. Our adjusted $R^{2}$ equals 0.205 .

2) Predictive relevance $\left(Q^{2}\right)$ : This statistic is obtained by the sample re-use technique 'Blindfolding'. Omission distance is set between 5 and 10, where the number of observations divided by the omission distance is not an integer [28]. For example, if you select an omission distance of 7 , then every 7 th data point is omitted and parameters are estimated with the remaining data points. Estimated parameters help predict the omitted data points and the difference between the actual omitted data points and the predicted data points becomes the input to the calculation of $Q^{2}$. Blindfolding is applied to endogenous constructs with reflective indicators. It is indicative of the path model's predictive relevance in the context of the endogenous construct if $Q^{2}$ is higher than zero. $Q^{2}$ is 0.049 (low).

3 ) Assessing the relative impact of predictive relevance $\left(q^{2}\right)$ : Following on from the above analysis of predictive relevance, $q^{2}$ effect size can be calculated by excluding the exogenous constructs one at a time ([28], p.207). According to reference [28] and [46], an effect size of 0.02 is considered small, 0.15 is moderate and 0.35 is large. Excluding complexity and uncertainty constructs one at a time results in $q^{2}$ values of 0.009 (low) and 0.048 (low), respectively.

4) Assessing the effect sizes $\left(f^{2}\right)$ : This statistic measures the importance of the exogenous constructs in explaining the endogenous construct and it re-calculates $R^{2}$ by omitting one exogenous construct at a time. Again, an effect size of 0.02 is small, 0.15 is moderate and 0.35 is large. $f^{2}$ equals 0.200 (moderate) when the complexity exogenous construct is omitted, and $f^{2}$ is 0.007 (low) when the uncertainty exogenous construct is omitted.

Let us summarise the original analysis before deletion of indicators. The internal consistency and discriminant validity of the reflective measurement model is healthy; however, there are some questions about indicator reliability (one reflective indicator is highlighted for removal) and convergent validity. With the formative measurement model, collinearity among indicators is not an issue, but convergent validity is low, and three formative indicators are highlighted for deletion. Regarding the structural model, predictive accuracy and relevance are low and other criteria such as effect size is mixed.

We proceed to delete the reflective indicator non-concessional contributions, and formative indicators children, health and insurance, and re-run the analysis (see Figure 3). The adjusted $R^{2}$ is the same at 0.205 but other criteria improve. Composite reliability (internal consistency) rises from 0.648 to 0.660 ; average variance extracted (convergent validity) rises from 0.293 to $0.348 ; Q^{2}$ (predictive relevance) rises from 0.049 to 0.060 ; and, $q^{2}$ (relative impact of predictive relevance) values rise to 0.010 and 0.060 .

\subsection{Robustness Tests}

We now focus on the sub-sample " 51 years or older" with the reduced model (N 


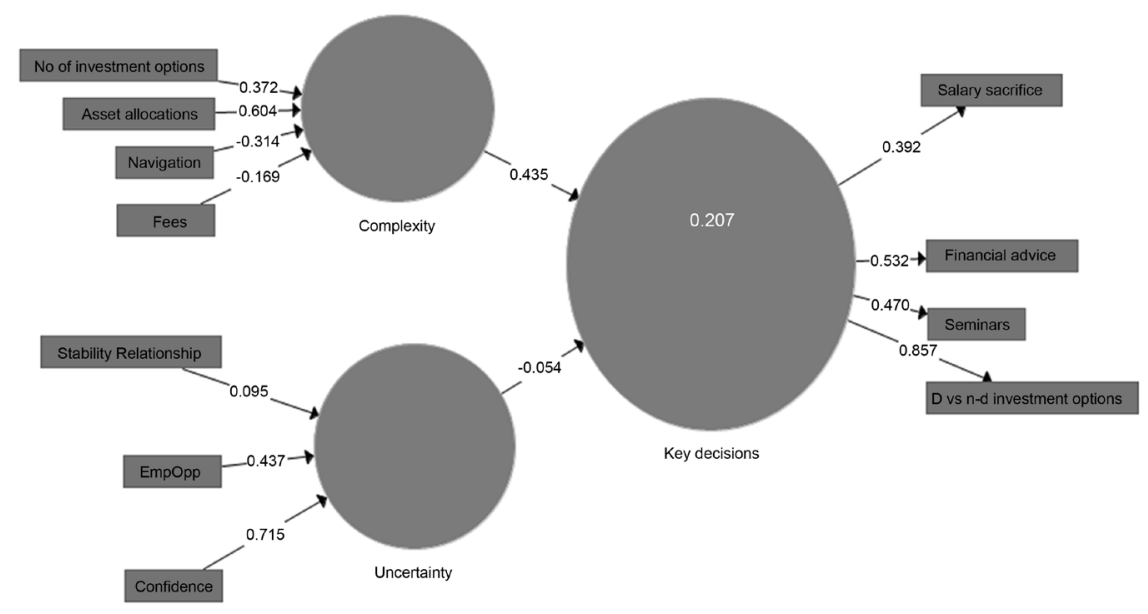

Figure 3. PLS-SEM analysis with the reduced model.

= 208) to ascertain whether analysing data across all age groups distorts the findings. Basic findings are reported in Figure 4. The adjusted $R^{2}$ rises from 0.205 to 0.241 . Composite reliability (internal consistency) drops from 0.660 to 0.598 ; average variance extracted (convergent validity) slightly drops from 0.348 to $0.333 ; Q^{2}$ (predictive relevance) drops from 0.060 to 0.053 ; and, $q^{2}$ (relative impact of predictive relevance) rises from 0.010 to 0.014 (complexity omitted), and drops from 0.060 to 0.053 (uncertainty omitted). Overall, the outer weights and loadings and path coefficients are of the same order, which indicates that using the larger sample (across all age groups) is not introducing problems into the results.

An alternative to PLS-SEM was introduced by [47] [48] as generalized structured component analysis (GSCA). We apply GSCA as a robustness test because it belongs to the same family of methods. Both PLS-SEM and GSCA are variance-based methods appropriate for predictive modelling and they substitute components for factors. GSCA retains the advantages of PLS-SEM such as fewer restrictions on distributional assumptions (i.e. multivariate normality of observed variables is not required for parameter estimation), unique component score estimates, and avoidance of improper solutions with small samples [47], [49]. As reference ([50], p.174) clearly point out “...comparison of PLS to other methods cannot and should not be applied indiscriminately." We re-state that CB-SEM is not a feasible or meaningful alternative to PLS-SEM under the conditions of the current study, where the sample size is small compared to the population, formative indicators are present and the theorised model is exploratory.

We use the web-based GSCA software GeSCA (http://www.sem-gesca.org/) for robustness testing. As can be seen in Table 2, the main PLS-SEM results are confirmed by GSCA, i.e. the statistical criteria are in the same range. For example, AVE is close to each other; outer loadings are of similar magnitude across the reflective indicators; the path coefficient is statistically significant in the structural model; and, the coefficients of determination are low. 


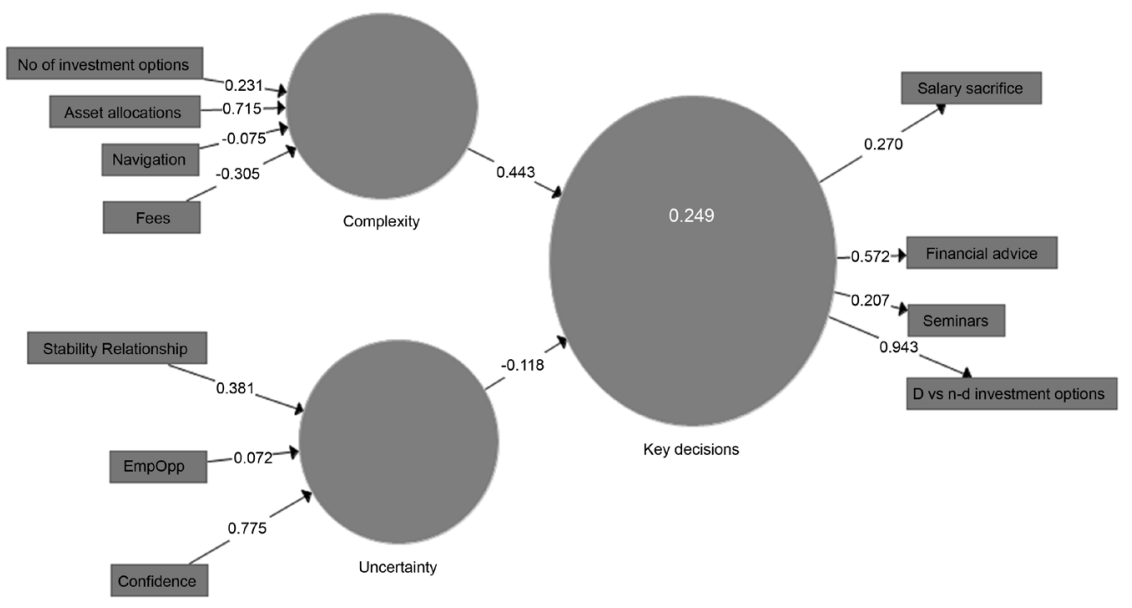

Figure 4. PLS-SEM analysis with the sub-sample (reduced model)

Table 2. Robustness testing on the original model and the reduced model.

\begin{tabular}{ccccc}
\hline & PLS-SEM & GSCA & $\begin{array}{c}\text { PLS-SEM } \\
\text { (reduced) }\end{array}$ & $\begin{array}{c}\text { GSCA } \\
\text { (reduced) }\end{array}$ \\
\hline Measurement model & & & & \\
Average variance extracted (AVE) & 0.293 & 0.332 & 0.348 & 0.391
\end{tabular}

Outer loadings of reflective indicators

$$
\text { Salary sacrifice }
$$

Non-concessional contributions

Financial advice

$$
\text { Seminars }
$$

Default/non-default investment options

Structural model (path coefficients)

$$
\text { Complexity }
$$

Uncertainty

Coefficient of determination $\left(\mathrm{R}^{2}\right)$

$\begin{array}{cccc}0.396 & 0.504 & 0.392 & 0.509 \\ 0.303 & 0.428 & \text { Dropped } & \text { Dropped } \\ 0.539 & 0.693 & 0.532 & 0.706 \\ 0.475 & 0.667 & 0.470 & 0.684 \\ 0.837 & 0.545 & 0.857 & 0.580 \\ & & & \\ 0.422 & 0.352 & 0.435 & 0.371 \\ -0.079 & -0.097 & -0.054 & -0.076 \\ 0.205 & 0.139 & 0.205 & 0.143\end{array}$

\section{Concluding Remarks}

We undertook this research project to explain key decisions taken by UniSuper members, such as salary sacrificing. Based on an online survey, complexity appears to explain key decisions more than uncertainty. Overall, the variation in key decisions explained jointly by complexity and uncertainty is $20.5 \%$. We ran two robustness tests, namely, a smaller sample (51 years or older) with PLS-SEM, and a generalized structured component analysis, which belongs to the same family of methods as PLS-SEM. Both approaches gave the same order of results, confirming that PLS-SEM results are robust.

We then proceeded to look at the open-ended questions posed under each section (see the Appendix) to explain the level of variation. Under key decisions 
taken by members, some people's response is that they do not understand key decisions regarding superannuation. One respondent writes, "The complexity of rules and terminology are over-whelming to the average person". Another writes, "I doubt that I made the right decision personally contributing to super. The govts are $100 \%$ trustworthy that they will move the goalposts that I am planning my financial future upon. This is my money and they have forgotten that!" Other examples are: "I actually have no idea about my super", "I have no financial literacy, the share market is too volatile and I am unable to afford the high cost financial advice which I believe should be at no cost to members", and so on.

Under complexity, the open-ended question attracted comments such as "Lack of financial literacy in the population", "Frequent rule changes, grandfathering, slow responses from UniSuper", "Government changing the superannuation rules constantly", "As UniSuper only provides a total balance, there is no transparency on number of units held and their value and the performance with time", and "the multitude of options to choose from", and so on.

Under uncertainty, the open-ended question attracted comments such as "Riskiness of investments", "Not knowing what health or medical issues you could face and ensuring your insurance is appropriate", "stability of investments, do I get the money later in my life?", "Govt changes and not knowing what is really enough and do not have the knowledge and skills to understand super", and "I have no idea what I should be doing to get the most out of superannuation", and so on. The full list of comments to the open-ended questions is available from the corresponding author.

Based on the above sample of comments, it is not surprising that key decisions cannot be explained fully by questions on complexity and uncertainty. Clearly, UniSuper members are at a loss as to how to make key decisions for their future, partly due to non-transparency of superannuation and governments changing rules. This problem makes research in this area difficult until superannuation is simplified.

We propose different variables to increase the coefficient of determination. Regarding complexity and uncertainty, we suggest future researchers examine the policies of regulators/government. Regarding key decisions, a survey is important to highlight the decisions taken by members.

\section{References}

[1] APRA (2017) Statistics: Annual Superannuation Bulletin. Australian Prudential Regulation Authority, February 2017.

https://www.apra.gov.au/media-centre/media-releases/apra-releases-superannuatio n-statistics-december-2016

[2] Cummings, J. (2016) Effect of Fund Size on the Performance of Australian Superannuation Funds. Accounting and Finance, 56, 695-725.

https://doi.org/10.1111/acfi.12110

[3] OECD (2015) Pension Markets in Focus. Organisation for Economic Co-Operation 
and Development.

http://www.oecd.org/pensions/Pension-Markets-in-Focus-2015.pdf

[4] Gerrans, P. and Yap, G. (2014) Retirement Savings Investment Choices: Sophisticated or Naïve? Pacific-Basin Finance Journal, 30, 233-250.

https://doi.org/10.1016/j.pacfin.2014.10.005

[5] Ganegoda, A. and Evans, J. (2017) The Australian Retirement Lottery: A System Failure. Australian Journal of Management, 42, 3-31. https://doi.org/10.1177/0312896214554267

[6] Cheah, K., Foster, F., Heaney, R., et al. (2015) Discussions on Long-Term Financial Choice. Australian Journal of Management, 40, 414-434. https://doi.org/10.1177/0312896214532476

[7] Gan, S., Heaney, R. and Gerrans, P. (2015) Individual Investor Portfolio Performance in Retirement Savings Accounts. Australian Journal of Management, 40, 652-671. https://doi.org/10.1177/0312896214528187

[8] Feng, J. (2014) The Effect of Superannuation Tax Incentives on Salary Sacrifice Participation. Economic Record, 90, 59-73. https://doi.org/10.1111/1475-4932.12131

[9] Borowski, A. (2013) Risky by Design: The Mandatory Private Pillar of Australia's Retirement Income System. Social Policy \& Administration, 47, 749-764. https://doi.org/10.1111/spol.12041

[10] Bateman, H., Echert, C., Geweke, J., et al. (2012) Financial Competence and Expectations Formation: Evidence from Australia. The Economic Record, 88, 39-63. https://doi.org/10.1111/j.1475-4932.2011.00766.x

[11] Bikker, J., Steenbeek, O. and Torracchi, F. (2012) The Impact of Scale, Complexity, and Service Quality on the Administrative Costs of Pension Funds: A CrossCountry Comparison. The Journal of Risk and Insurance, 79, 477-514. https://doi.org/10.1111/j.1539-6975.2011.01439.x

[12] Borowski, A. (2009) The Certainty of Uncertainty: Superannuation and Globalization. Health Sociology Review, 18, 364-378. https://doi.org/10.5172/hesr.2009.18.4.364

[13] The Treasury (2014) Financial System Inquiry: Final Report, November. http://fsi.gov.au/files/2014/12/FSI_Final_Report_Consolidated20141210.pdf

[14] Gharghori, P., Sujoto, C. and Veeraraghavan, M. (2008) Are Australian Investors Smart? Australian Journal of Management, 32, 525-544. https://doi.org/10.1177/031289620803200308

[15] Burnett, J., Davis, K., Murawski, C., et al. (2014) Measuring Adequacy of Retirement Savings. Melbourne Institute Working Paper Series No.5/14, Faculty of Business \& Economics, The University of Melbourne.

[16] Superguide (2018).

https://www.superguide.com.au/boost-your-superannuation/superannuation-guara ntee-rate

[17] Humphrey, J., Benson, K., Low, R., et al. (2015) Is Diversification Always Optimal? Pacific-Basin Finance Journal, 35, 521-532. https://doi.org/10.1016/j.pacfin.2015.09.003

[18] Gerrans, P. (2012) Retirement Savings Investment Choices in Response to the Global Financial Crisis: Australian Evidence. Australian Journal of Management, 37, 415-439. https://doi.org/10.1177/0312896212450041

[19] Earl, J., Gerrans, P., Asher, A., et al. (2015) Financial Literacy, Financial Judgement, and Retirement Self-Efficacy of Older Trustees of Self-Managed Superannuation 
Funds. Australian Journal of Management, 40, 435-458. https://doi.org/10.1177/0312896215572155

[20] Benjamin, D., Shapiro, J. and Brown, S. (2013) Who Is "Behavioral"? Cognitive Ability and Anomalous Preferences. Journal of the European Economic Association, 11, 1231-1255. https://doi.org/10.1111/jeea.12055

[21] Kahneman, D. and Tversky, A. (1974) Judgement under Uncertainty: Heuristics and Biases. Science, 185, 1124-1131. https://doi.org/10.1126/science.185.4157.1124

[22] Hastings, J., Madrian, B. and Skimmyhorn, W. (2013) Financial Literacy, Financial Education, and Economic Outcomes. Annual Review of Economics, 5, 347-373. https://doi.org/10.1146/annurev-economics-082312-125807

[23] Lohmöller, J. (1989) Latent Variable Path Modelling with Partial Least Squares. Physica-Verlag, Heidelberg. https://doi.org/10.1007/978-3-642-52512-4

[24] Wold, H. (1982) Soft Modeling: The Basic Design and Some Extensions. In: Jöreskog, K.G. and Wold, H.O.A., Eds., Systems under Indirect Observations: Part II, North-Holland, Amsterdam, 1-54.

[25] Hair, J., Sarstedt, M., Pieper, T., et al. (2012) The Use of Partial Least Squares Structural Equation Modeling in Strategic Management Research: A Review of Past Practices and Recommendations for Future Applications. Long Range Planning, 45, 320-340. https://doi.org/10.1016/j.lrp.2012.09.008

[26] Henseler, J., Dijkstra, T., Sarstedt, M., et al. (2014) Common Beliefs and Reality about Partial Least Squares: Comments on Rönkkö \& Evermann (2013). Organizational Research Methods, 17, 182-209. https://doi.org/10.1177/1094428114526928

[27] Hair, J., Sarstedt, M., Hopkins, L., et al. (2014) Partial Least Squares Structural Equation Modeling (PLS-SEM): An Emerging Tool in Business Research. European Business Review, 26, 106-121. https://doi.org/10.1108/EBR-10-2013-0128

[28] Hair, J., Hult, G., Ringle, C., et al. (2017) A Primer on Partial Least Squares Structural Equation Modeling (PLS-SEM). 2nd Edition, Sage Publications, Thousand Oaks.

[29] Lee, L., Petter, S., Fayard, D., et al. (2011) On the Use of Partial Least Squares Path Modeling in Accounting Research. International Journal of Accounting Information Systems, 12, 305-328. https://doi.org/10.1016/j.accinf.2011.05.002

[30] Avkiran, N. (2017) An In-Depth Discussion and Illustration of Partial Least Squares Structural Equation Modeling in Health Care. Health Care Management Science. https://doi.org/10.1007/s10729-017-9393-7

[31] Ringle, C., Sarstedt, M. and Straub, D. (2012) Editor's Comments: A Critical Look at the Use of PLS-SEM in "MIS Quarterly". MIS Quarterly, 36, 3-14. http://www.jstor.org/stable/41410402

[32] Hair, J., Sarstedt, M., Ringle, C., et al. (2012) An Assessment of the Use of Partial Least Squares Structural Equation Modeling in Marketing Research. Journal of the Academy of Marketing Science, 40, 414-433. https://doi.org/10.1007/s11747-011-0261-6

[33] Peng, D. and Lai, F. (2012) Using Partial Least Squares in Operations Management Research: A Practical Guideline and Summary of Past Research. Journal of Operations Management, 30, 467-480. https://doi.org/10.1016/j.jom.2012.06.002

[34] Kaufmann, L. and Gaeckler, J. (2015) A Structured Review of Partial Least Squares in Supply Chain Management Research. Journal of Purchasing and Supply Management, 21, 259-272. https://doi.org/10.1016/j.pursup.2015.04.005

[35] do Valle, P. and Assaker, G. (2016) Using Partial Least Squares Structural Equation 
Modeling in Tourism Research: A Review of Past Research and Recommendations for Future Applications. Journal of Travel Research, 55, 695-708. https://doi.org/10.1177/0047287515569779

[36] Tenenhaus, M., Vinzi, V., Chatelin, Y., et al. (2005) PLS Path Modeling. Computational Statistics \& Data Analysis, 48, 159-205. https://doi.org/10.1016/j.csda.2004.03.005

[37] Avkiran, N., Ringle, C. and Low, R. (2018) Monitoring Transmission of Systemic Risk: Application of PLS-SEM in Financial Stress Testing. The Journal of Risk, 20, 83-115. https://doi.org/10.21314/JOR.2018.386

[38] Jöreskog, K. (1979) Basic Ideas of Factor and Component Analysis. In: Jöreskog, K.G. and Sörbom, D., Eds., Advances in Factor Analysis and Structural Equation Models, University Press of America, New York, 5-20.

[39] Wu, W., Lan, L. and Lee, Y. (2012) Exploring the Critical Pillars and Causal Relations within the NRI: An Innovative Approach. European Journal of Operational Research, 218, 230-238. https://doi.org/10.1016/j.ejor.2011.10.013

[40] Evermann, J. and Tate, M. (2016) Assessing the Predictive Performance of Structural Equation Model Estimators. Journal of Business Research, 69, 4565-4582. https://doi.org/10.1016/j.jbusres.2016.03.050

[41] Shmueli, G., Ray, S., Velasquez Estrada, J., et al. (2016) The Elephant in the Room: Evaluating the Predictive Performance of PLS Models. Journal of Business Research, 69, 4552-4564. https://doi.org/10.1016/j.jbusres.2016.03.049

[42] Henseler, J., Ringle, C. and Sinkovics, R. (2009) The Use of Partial Least Squares Path Modeling in International Marketing. New Challenges to International Marketing. Advances in International Marketing, 20, 277-319.

[43] Ringle, C.M., Wende, S. and Becker, J.M. (2015) SmartPLS 3. SmartPLS GmbH, Bönningstedt. http://www.smartpls.com

[44] Hair, J., Ringle, C. and Sarstedt, M. (2011) PLS-SEM: Indeed a Silver Bullet. Journal of Marketing Theory and Practice, 19, 139-151. https://doi.org/10.2753/MTP1069-6679190202

[45] Chin, W. (2010) How to Write Up and Report PLS Analyses. In: Vinzi, V.E., Chin, W.W., Henseler, J. and Wang, H., Eds., Handbook of Partial Least Squares: Concepts, Methods and Applications, Springer Handbooks of Computational Statistics Series, Vol. II, Springer, Heidelberg, Dordrecht, London, New York, 655-690. https://doi.org/10.1007/978-3-540-32827-8_29

[46] Hair, J., Ringle, C. and Sarstedt, M. (2013) Partial Least Squares Structural Equation Modeling: Rigorous Applications, Better Results and Higher Acceptance. Long Range Planning, 46, 1-12. https://doi.org/10.1016/j.lrp.2013.01.001

[47] Hwang, H. and Takane, Y. (2004) Generalized Structured Component Analysis. Psychometrika, 69, 81-99. https://doi.org/10.1007/BF02295841

[48] Hwang, H. and Takane, Y. (2014) Generalized Structured Component Analysis: A Component-Based Approach to Structural Equation Modeling. Chapman \& Hall, New York.

[49] Hwang, H., Ho, M. and Lee, J. (2010) Generalized Structured Component Analysis with Latent Interactions. Psychometrika, 75, 228-242. https://doi.org/10.1007/s11336-010-9157-5

[50] Marcoulides, G., Chin, W. and Saunders, C. (2009) A Critical Look at Partial Least Squares Modeling. MIS Quarterly, 33, 171-175. https://doi.org/10.2307/20650283 


\section{Appendix: The Survey Instrument}

This is a survey directed at UniSuper members. The research question is about explaining key decisions taken by members of UniSuper impacted by complexity and uncertainty. Please answer the following questions to the best of your ability, and complete the demographic information at the end (scoring is indicated in round brackets).

Key decisions taken by you

1) Do you salary sacrifice? i.e. before-tax voluntary (concessional) contributions. Yes (1) or No (0)

If Yes, what are the benefits you enjoy in addition to before-tax contribution to your superannuation? (add 2 more marks for each item below)
a) $\mathrm{Car}$
b) Car parking
c) Property
d) Expense payments (e.g. loan repayments, school fees, child care costs, home phone costs)

e) Portable electronic device

f) Computer software

g) Briefcase

h) Other (please specify)

2) Do you make after-tax (non-concessional) contributions? i.e. member contributions where no income tax deduction is claimed. Yes (1) or No (0)

If Yes, what are the benefits you enjoy in addition to after-tax contribution to your superannuation? (add 2 more marks for each item below)

a) Contributions your spouse makes to your superannuation fund

b) Excess before-tax (concessional) contributions

c) Transfers from foreign superannuation funds

d) Other (please specify)

3) Approximately how many times have you sought financial advice since you joined UniSuper?

$0 ; 1 ; 2 ; 3 ; 4 ; 5$ or more times

4) Approximately how many times have you attended educational seminars on superannuation since you joined UniSuper?

$0 ; 1 ; 2 ; 3 ; 4 ; 5$ or more times

5) Which investment option(s) do you hold in UniSuper? ${ }^{3}$ (see footnote for scoring)

Default (pre-mixed) option, e.g. Capital stable, Conservative Balanced, Balanced, etc.

${ }^{3}$ Scoring system based on performance objectives and expected frequency of negative annual return (higher score indicates a more risky investment) - Pre-mixed options. Capital stable (1); Conservative balanced (2); Balanced (3); Sustainable balanced (4); Growth (5); Sustainable high growth (6); High growth (6). Sector options. Cash (1); Australian bond (2); Diversified credit income (3); Australian equity income (4); Listed property (5); Global environmental opportunities (6); International shares (6); Australian shares (7); Global companies in Asia (7). If multiple items are indicated, we assume equal weights and take the average score. 
Please specify the name(s) of the default investment option(s) you hold:
a) Capital stable
b) Conservative balanced
c) Balanced
d) Sustainable balanced
e) Growth
f) Sustainable high growth
g) High growth

Non-default (sector) option, e.g. Cash, Australian Bond, Listed Property, etc.

Please specify the name(s) of the non-default investment option(s) you hold:
a) Cash
b) Australian bond
c) Listed property
d) Australian shares
e) International shares
f) Global environmental opportunities
g) Australian equity income
h) Global companies in Asia
i) Diversified credit income
j) I don't know (0)

6) Open-ended question: In your opinion, are there other key decisions not covered above?

Complexity: Do certain features of UniSuper make your key decisions more difficult?

1) Do you perceive insurance products in UniSuper (e.g. death benefit, total and permanent disablement benefit, and income protection cover) difficult to follow?

1 (Simple); 2; 3; 4; 5 (Complex)

2) What number of investment options (e.g. pre-mixed such as Conservative Balanced, or sector such as Listed Property) in UniSuper would make your choice more difficult?

$2 ; 4 ; 6 ; 8 ; 10$ or above

3) What is the number of strategic asset allocations in your chosen investment option, i.e. cash and fixed interest, Australian shares, property, etc.? (select the nearest number)

$1 ; 2 ; 4 ; 6 ; 8$ or above; I don't know (0)

4) What is the ease of navigation on UniSuper website?

1 (Easy); 2; 3; 4; 5 (Difficult)

5) Are fees and charges in UniSuper difficult to understand?

1 (Easy to understand); 2; 34; 5 (Difficult to understand)

6) Open-ended question: In your opinion, what makes superannuation complex?

Uncertainty: Do your personal circumstances make it more difficult to arrive 
at key decisions?

1) Does the stability of your current relationship(s) impact your feelings of uncertainty regarding superannuation?

1 (Low); 2; 3; 4; 5 (High)

2) Does having children impact uncertainty?

1 (Low); 2; 3; 4; 5 (High)

3) Do your employment opportunities impact uncertainty?

1 (Low); 2; 3; 4; 5 (High)

4) Does your health impact uncertainty?

1 (Low); 2; 3; 4; 5 (High)

5) Does your confidence in handling retirement savings impact uncertainty?

1 (Low); 2; 3; 4; 5 (High)

6) Open-ended question: In your opinion, what makes superannuation uncertain?

Demographic information

Male or Female

Single; De facto relationship; Married; Other

Number of dependents

Your age group: 18 - 25; 26 - 30; 31 - 35; 36 - 40; 41 - 45; 46 - 50; 51 - 55; 56 or older

Highest degree achieved: Bachelors; Masters; PhD; Other

Employment status: Full-time, Part-time, or Casual/sessional

Member's income bracket: Less than $\$ 10,000 ; \$ 10,000-40,000 ; \$ 40,001$ 60,$000 ; \$ 60,001-80,000 ; \$ 80,001-100,000 ; \$ 100,001-120,000 ; \$ 120,001-$ 140,000; \$140,001 - 160,000; Above $\$ 160,000$

Approximate years you have been with UniSuper. 